International Journal of Agriculture and Environmental Research

ISSN: 2455-6939

Volume: 07, Issue: 04 "July-August 2021"

\title{
SOIL PROTISTS COMMUNITY COMPOSITION UNDER DIFFERENT VINEYARD FLOOR MANAGEMENT TYPE
}

\author{
Salvador Rodríguez - Zaragoza ${ }^{\mathrm{a}}$, G. Eshel ${ }^{\mathrm{b}}$, Tirtza Doniger ${ }^{\mathrm{c}}$, \\ Chen Sherman ${ }^{c}$ and Y. Steinberger ${ }^{\text {** }}$ \\ aLaboratorio de Ecología Microbiana, Unidad de Biotecnología y Prototipos, FES Iztacala, UNAM. Avenida de los \\ Barrios \#1, Los Reyes Iztacala Estado de México, 54090, México. \\ ${ }^{\mathrm{b} S o i l ~ E r o s i o n ~ R e s e a r c h ~ S t a t i o n, ~ M i n i s t r y ~ o f ~ A g r i c u l t u r e ~ \& ~ R u r a l ~ D e v e l o p m e n t, ~ B e i t-D a g a n, ~ 5020000, ~ I s r a e l . ~}$ \\ 'The Mina and Everard Goodman Faculty of Life Sciences, Bar-Ilan University, Ramat-Gan, Israel. \\ *Corresponding Author
}

DOI: https://doi.org/10.51193/IJAER.2021.7403

\begin{abstract}
The increasing social consciousness about the need for environmental-friendly agro-products and services has motivated the development of sustainable and organic agriculture. Cultivated lands compose a patchy landscape where conventional, organic and conservation agriculture are intermixed. Sustainable management (SA) in vineyards aims to improve and sustain productivity without sacrificing profits by minimum mechanical soil disturbances, permanent organic soil cover and use of advanced biological controls of pests and weeds. Organic management (OA) avoids using herbicides, pesticides and synthetic fertilizers, which are commonly used in conventional farming (CF). These approaches rely on bacterial and fungal mobilization of nutrients from the soil to the root system controlled by microbial. As plant productivity is secondarily related to protozoa, we aim to determine the effect of vineyard management kinds on soil protozoa community. We expected to find higher protists' diversity in sustainable agriculture correlated to the increase in soil organic matter. All soil managements impacted positively the 8 Classes that count for $70 \%$ of the protists while having a variable impact on other dominant Classes and Molecular Operational Taxonomic Units (representing genus and species).Contrary to what was expected, protozoa diversity was higher in the $\mathrm{CF}(\mathrm{H}=4.34)$ followed by $\mathrm{SA}(\mathrm{H}=$ 4.04) and $\mathrm{OA}(\mathrm{H}=4.035)$. Water availability: $\mathrm{C} / \mathrm{N}$ and salinity were the main factors explaining MOTU's variances. We concluded that farming management promoted the incorporation of organic matter into soil, favouring higher diversity of cultivated soils in comparison to the control one.
\end{abstract}


International Journal of Agriculture and Environmental Research

ISSN: 2455-6939

Volume: 07, Issue: 04 "July-August 2021"

Keywords: Abiotic variables, Agricultural management, Molecular identification, Protozoa diversity, Soil protozoa community, Vineyard

\section{INTRODUCTION}

Traditional agricultural practices impair several ecosystem services, such as clean water and $\mathrm{CO}_{2}$ sequestering, by perturbing the soil system. Additionally, concerns for public health and environmental sustainability have been on the rise because of the heavy use of agrochemicals needed to satisfy the increasing demand for goods and services, returning to market demand for eco-friendly and sustainable agricultural products from farmlands (Boye \& Arcand, 2013).

The first kind of management designed for recovering and preserving soils used in conventional farming systems includes the adoption of the Conservation Agriculture principles, mainly the organic agriculture (OA) and sustainable (SA) agriculture systems. According to FAO, this approach aims at improving and sustaining productivity, increasing profits and food security while preserving and enhancing the basic resources and the environment (FAO, 2017). Conservation management in vineyards and orchard is characterized by three linked principles: 1. Continuous, minimal, or no mechanical soil disturbance (i.e. zero tillage and direct sowing or broadcasting of crops seeds; direct placing of planting materials in soil; minimum soil disturbance from cultivation, harvesting or farm traffic; and in special occasions limited strip tillage); 2. Permanent organic soil cover, especially by service crops and its residues; 3. Diversification of service crops, including a balanced mix of legume and non-legume crops grown in-between the orchard or vineyard trees (Kassam et al., 2015; Palm et al., 2014).

Agronomic activity should be carried out by using advanced techniques of biological control for pests and diseases. Under organic management, the pesticides must be of plant or mineral source origin (Hamadttu, 2019). Both sustainable and organic agriculture use mechanical weed management and are based on organic nutrient source such as compost or compost tea. In sustainable agriculture, herbicides, if used, only in very problematic spots and are very rarely applied and never as pre-emergence or a systemic type.

All organic matter added to soils will be metabolized by different groups of bacteria and fungi, many of them in intimate contact with the plants' root system. In this way, plants nutrition takes place by nutrient mobilization from the soil environment to the plant through root interactions with bacteria and fungi (Jacobi et al., 2017). Protists indirectly participate in plant nutrition by releasing nutrients immobilized in the microbial biomass they feed on (Bonkowski, 2004), i.e. protists consumption of bacteria significantly contributes to nitrogen availability as well as cycling other nutrients (Coleman, 1994; Crotty et al., 2012; Sina, et al., 2013). Thus, the soil protist community plays an important role in soil food webs, enhancing soil fertility by 
International Journal of Agriculture and Environmental Research

ISSN: 2455-6939

Volume: 07, Issue: 04 "July-August 2021"

increasing organic matter decomposition and improving soil structure, water, and air movement in the soil.

Among protists, ciliates and flagellates may be used as bio indicators of soil processes in agricultural systems due to their capacity of inhabiting all kind of soils, high numbers and diversity, short generational times and eco-physiological adaptability (Foissner, 1994, 1997). Given all these characteristics, we would expect that the protists community structure would change in response to long lasting environmental stresses, such as those occurring during conventional orchard management. However, morphological identification of ciliates and flagellates demands a high degree of expertise and is time consuming. Consequently, the quantity of sample repetitions and the laboriousness to review them, constrain the ability to identify meaningful patterns of change in the protist community. Molecular techniques open this possibility by allowing massive identification of the protists community structure from a larger number of samples.

Objective: The main objective was to correlate the community composition of protists with the kind of agriculture management (traditional, organic, and sustainable) in vineyards.

Hypothesis: We hypothesized that (1) soil organic matter content will increase from conventional, to organic, to sustainable agriculture, and (2) higher diversity of protists will be positively correlated with the organic matter content of the soil.

\section{SITE DESCRIPTION}

The study site is in the Upper Galilee, characterized by a Mediterranean climate, with a multiannual mean rainfall of $720 \mathrm{~mm}$. and a limestone hilly topography (about $700 \mathrm{~m}$ above sea level). Following the topographic characteristic, the soil in the region is relatively shallow and classified as Terra Rosa (Lithic Rhodoxeralfs) to dark Rendzina (Rendolls).

Soil samples were collected in December 2017 from seven commercial vineyard plots and a nearby uncultivated shrub land (as a control) that is used for periodic grazing. All study plots are in a radius of $1.2 \mathrm{~km}$ distance. The vineyards study sites are represented by three different types of vineyard management:

1. Two Merlot vineyard plots (planted in 1999 and 2009) were kept under conventional management (CA). In both vineyards, the weeds are controlled with herbicides twice a year, resulting $95-99 \%$ of vineyard floor is bare and free of any herbaceous vegetation. Pests and disease control are based on commercial pesticides. Both vineyards are operated by local farmers and located in the vicinity of Safsufa $\left(33^{\circ} 00^{\prime} 18.6^{\prime \prime} \mathrm{N}\right.$ $35^{\circ} 25^{\prime} 46.8^{\prime \prime} \mathrm{E}$ and $\left.33^{\circ} 00^{\prime} 40.1^{\prime \prime} \mathrm{N} 35^{\circ} 25^{\prime} 33.6^{\prime \prime} \mathrm{E}\right)$. 
International Journal of Agriculture and Environmental Research

ISSN: 2455-6939

Volume: 07, Issue: 04 "July-August 2021"

2. Three vineyard plots grown under certified Organic management (OA) by Kibbutz Tziv'on (3301'13.1"N 35 25'20.8"E).Cabernet Sauvignon was planted in 2005, Syrah in 2006 and Sauvignon Blank in 2013. In the three plots, compost is used as the main fertilizer (about $50 \mathrm{~m}^{3} \mathrm{ha}^{-1}$ every second year and compost tea from time to time). The vineyard soil is fully covered by local herbaceous vegetation managed by mowing once or twice a year in the spring with no use of any herbicide. Biological pest control techniques are used when a threat is detected.

3. Two vineyard plots grown under the sustainable management (SA) located at $33^{\circ} 02^{\prime} 05.4^{\prime \prime N} 35^{\circ} 24^{\prime} 27.0^{\prime \prime E}$ : the Barbera planted in 2007 and the Syrah in 2008. Both vineyards are cultivated using sustainable viticulture practices: no chemical herbicides are applied, and advanced pest management techniques are used, and $100 \%$ of vineyard floors are covered with local herbaceous vegetation.

4. The control plot $(\mathrm{Ct})$ was an uncultivated shrub land nearby the 1999 Merlot plots. It is typical Mediterranean scrubland and is occasionally used for cattle grazing.

\section{SOIL SAMPLING}

Soil samples were collected from 7vineyard plots in the fall of 2017. Nine sampling repetitions from each vineyard plot were taken from the tops soil $(0-5 \mathrm{~cm})$ in the zone between rows (interrows). Repetitions were taken, recorded, and processed individually as independent samples. In addition, eight samples were taken from $0-5 \mathrm{~cm}$ of the topsoil layer after withdrawing the litter from the control plot. Soil samples were individually placed in sealed plastic bags and kept in a cooling block until their arrival to the lab (less than 24h). Upon arrival, samples were stored at $4^{\circ} \mathrm{C}$ during the analysis period.

The following soil physical measurements were undertaken for each sample:

Soil moisture (SM) content was determined gravimetrically by drying soil samples for $48 \mathrm{~h}$ at $105^{\circ} \mathrm{C}$ (expressed as percentage of dry weight).

Organic matter content (OM). A dry soil sample was placed in a muffle furnace at $390^{\circ} \mathrm{C}$ for $8 \mathrm{~h}$.

Soil pH and soil Electrical Conductivity (EC) were measured in an extraction of 1:2 airdried soil (sieved $<0.2 \mathrm{~mm}$ ) distilled water with a pH meter.

Soil Bulk Density $\left(\boldsymbol{B}_{\boldsymbol{d}}\right)$ was defined using undisturbed soil samples which were dried in an oven for 24 hours at $105^{\circ} \mathrm{C}$ and weighted.

$$
B_{d}=\frac{W_{\text {oven }- \text { dry soil }}}{\text { cylinder volume }}
$$


International Journal of Agriculture and Environmental Research

ISSN: 2455-6939

Volume: 07, Issue: 04 "July-August 2021"

Water Field Capacity (WFC) was determined around the arrival at the lab by weighing, drying in the oven for 24 hours at $105^{\circ} \mathrm{C}$ and then reweighing the samples.

$$
W F C=\frac{W_{\text {air-dry soil }}-W_{\text {oven-dry soil }}}{W_{\text {oven-dry soil }}}
$$

\section{Biotic Components of the Soil}

DNA Extraction: Genomic DNA was isolated from $0.5 \mathrm{~g}$ soil samples using the GeneAll ${ }^{\circledR}$ ExgeneTM soil DNA mini isolation kit (GeneAll Biotechnology, Korea). All DNA samples underwent Illumina sequencing. The recovered DNA sequences were processed in QIIMEver. 1.7.0 (Caporaso et al., 2010a; Caporaso et al., 2010b), using the pipeline for analyzing 18S rDNA sequence data. Default settings, along with UCLUST, were used for de novo selection of molecular operational taxonomic units (MOTUs) at 97\% similarity. The Silva 111 release (Yilmaz et al., 2014) was used as reference for taxonomical assignment of MOTUs. As the SILVA 111 database contained only an essential number of protists reads, we sought to reclassify the reads assigned to Protozoa in the QIIME classification by BLAST similarity analysis using a custom-made protist $18 \mathrm{~S}$ rDNA sequence database. The database enabled us the get better insight into the protist community. The R 'Bioconductor' package Phyloseqver 1.16.2 was used to draw the phylogenetic tree from the QUIIME data. All measurements were assessed using data from MOTUs with at least 5 reads in the overall dataset. After having the protists IDs for every MOTU, we intensively searched the on-line data bases for homologation of the taxonomic ranks to purge synonyms and check taxonomic grammar to achieve comparisons. After correcting taxonomic names, abundances were aggregated to the genus-species level, by keeping the identified taxonomic group plus sp as its MOTU marker from Family to higher taxonomic groups (i.e. Thecofilosea sp1 indicates that we identified one protist MOTU of that class).

\section{STATISTICAL ANALYSIS AND CALCULATIONS}

Physical and chemical soil measurements were analyzed after the percentages were arcsin transformed (Peck, 2010) and used for ANOVA and for CCA. MOTUs abundance data were aggregated by type of management to perform Canonical Correspondence Analysis (CCA) between protists abundances and soils physical properties. The natural log (ln) of taxa relative abundances were used for CCA and Polar Ordination (Bray Curtis) using the PC Ord® 7.0 for Windows ${ }^{\circledR}$ (Peck, 2010). Polar Ordination was set up with Hill method and using the time of day for randomization without specifying any other restriction. Relative MOTUs abundance was also used to calculate Shannon-Wiener's diversity index (H) and Simpson index (1-D) for each type of management. MOTUs turnover ( $\beta$ diversity) between type of managements and control 
soil was also calculated as well as the similarity between protists communities. This latter was achieved by using the PC Ord® 7.0 for Windows ${ }^{\circledR}$.

\section{RESULTS}

The sandy loam soil at Vineyard showed small variations in a pattern link to soil management practices (Table 1). Electric conductivity and organic matter showed an ascending pattern (Conventional < Organic < Sustainable); while pH and soil moisture showed a descending one (Sustainable < Organic < Conventional) and notoriously, the $\mathrm{C} / \mathrm{N}$ ratio was higher in the Organic management than the sustainable one (Table 1). Control soil was significantly different $(\mathrm{P}<0.01)$ from the managed soils in $\mathrm{pH}$, Moisture (\%) and Organic matter (\%), while showed no differences in salinity and the $\mathrm{C} / \mathrm{N}$ ratio (Table 1 ).

Table 1: Mean values of physical and chemical soil parameters at vineyards in the Upper Galilee

\begin{tabular}{|l|l|l|l|l|}
\hline & CF & SA & OA & Control \\
\hline $\mathrm{pH}$ & 7.66 & 7.33 & 7.5 & 7.27 \\
\hline EC & 373.6 & 774.34 & 536.65 & 491.98 \\
\hline SM \% & 8.75 & 6.11 & 8.48 & 0.06 \\
\hline OM \% & 3.69 & 6.82 & 5.31 & 17.65 \\
\hline C/N & 8.82 & 6.99 & 9.52 & 8.06 \\
\hline
\end{tabular}

$\mathrm{CF}=$ conventional farming (Conventional Management); $\mathrm{SA}=$ Sustainable Agriculture (Sustainable Management); (OA) = Organic Agriculture (Certified Organic Management) and Control $=$ Non-cultivated Soil. EC - Electric Conductivity $(\mu \mathrm{S} / \mathrm{cm}) ; \mathrm{SM}-$ soil moisture; $\mathrm{OM}$ - organic matter; $\mathrm{C} / \mathrm{N}$ - carbon nitrogen ratio.

Soil protists showed up in Upper Galilee with relatively high species richness, yielding 420 MOTUs based on the DNA sequences classified using the SILVA database. These MOTUs are distributed in 290 Families, 207 Orders and 64 Classes. Only 8 classes were the dominant ones accounting for $70 \%$ of protists, namely: Spirothrichea, Conodasida, Thecofilosea, Litostomatea, Phyllopharyngea, Sarcomonadea, Tubulinea and Chrysophysea, while only 4 super groups grouped the totality of protists: Amorphea, Haptista, Excavata, and TSAR (Burki et al., 2020) in Vineyard soils.

There were 29 dominant and common MOTUs, accounting for more than $65 \%$ of protist's relative abundance in the overall community at Vineyards. However, each type of agricultural 
management produced different proportions of dominant and common protists taxa (Fig.1). Agriculture management clearly have a negative impact in the relative abundances of the dominant and common MOTUs, except for Eugregarinorida sp1, that was more abundant under any type of agriculture than in the control soil, although its relative abundance was appreciably reduced in sustainable management. Hypotrichia sp1, on the other side, recovered its relative importance in sustainable agriculture. Oxitrichidae sp1, Thecofilosea, and most of the dominant and common MOTUs reduced their relative abundances in various degrees under agriculture management. Contrarily, rare taxa represented higher percentage of relative abundance along with higher number of total MOTUs in agriculture than in control soil (Fig. 1 and Table 2).

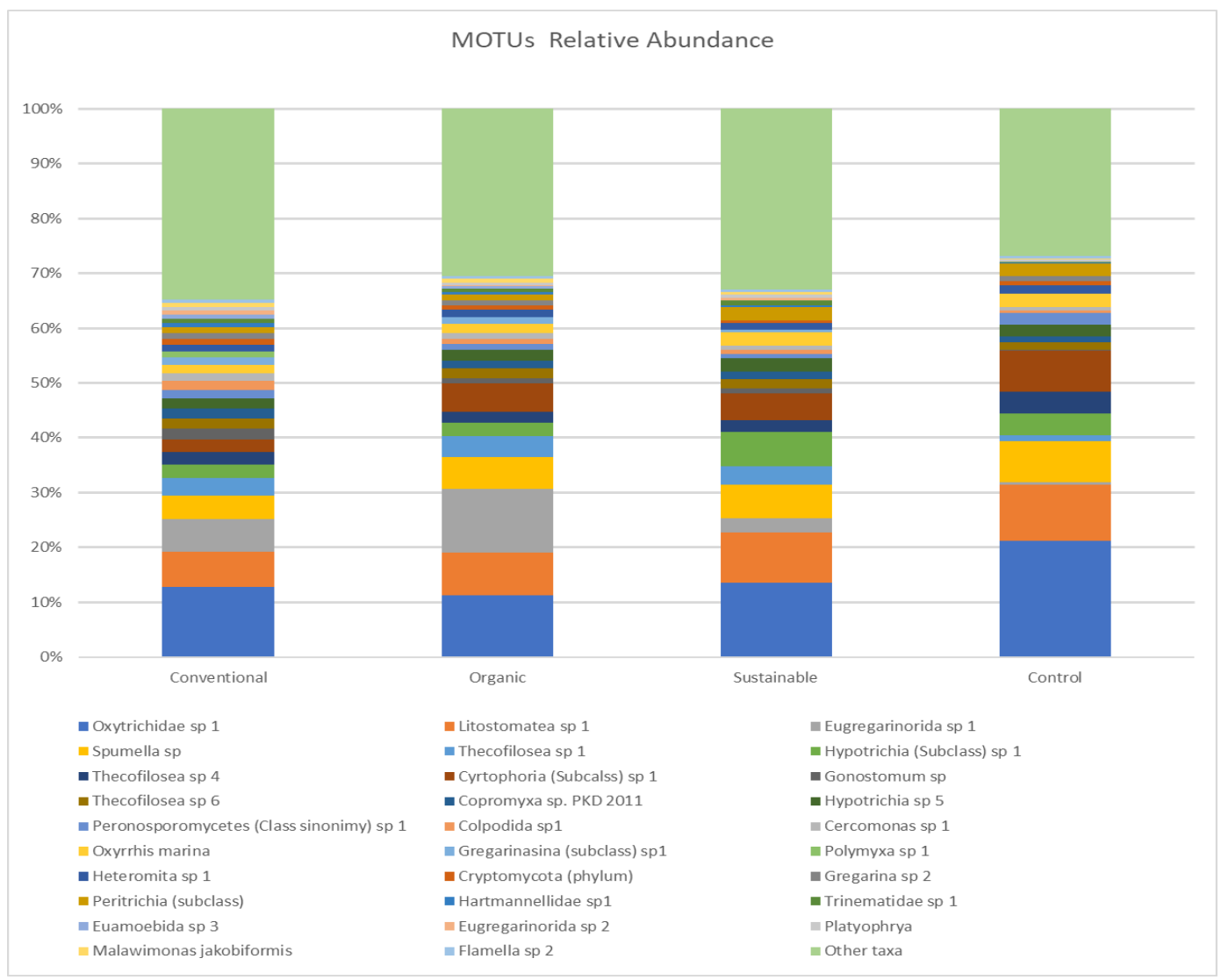

Fig. 1: Relative abundances of protists molecular operational taxonomic units (MOTUs) from different types of vineyard agriculture managements. The first 9 MOTUs are the dominant ones, followed by 20 common MOTUs. This 29 MOTUs comprised between $65 \%$ to $73 \%$ of the counts. The rare MOTUs comprises the remaining $27 \%$ to $35 \%$ of the counts in each management and control soil. The remaining rare species in the conventional management were 323, the organic one amounted for334, sustainable agriculture reached 308, and control soil showed 195. 
Table 2: Diversity values from cultivated soils at vineyards in the Upper Galilee

\begin{tabular}{|l|l|l|l|l|}
\hline & CF & SA & OA & Control \\
\hline S & 346 & 333 & 356 & 223 \\
\hline D (1-D) & 0.967 & 0.96 & 0.956 & 0.926 \\
\hline H' $^{\prime}$ & 4.34 & 4.04 & 4.035 & 3.56 \\
\hline$\beta$ control & 121 & 122 & 130 & \\
\hline$\beta C F$ & & 120 & 123 & \\
\hline$\beta$ SA vs OCA & & 129 & & \\
\hline
\end{tabular}

$\mathrm{CF}=$ conventional farming (Conventional Management); $\mathrm{SA}=$ Sustainable Agriculture (Sustainable Management); (OA) = Organic Agriculture (Certified Organic Management) and Control $=$ Non-cultivated Soil. D - Simpson diversity Index (1-D); S(H')- ShannonWiener diversity Index; $\beta$ diversity for each community.

The soil from organic agriculture showed the highest number of MOTUs (363) followed closely by CA and SA (Table 2), all of them appreciably more numerous than the 224 MOTUs found in the control soil. Diversity was positively affected in agriculture soils as revealed by the ShannonWiener diversity index and corroborated by the Simpson's index (1-D), leaving the control soil as the poorest location (Table 2). These differences are in tune with the turnover rate of $123-$ 132 MOTUs calculated between agriculture soils and the control one. However, turnover rate between agriculture soils was comparable to the ones obtained between each one of them and the control soil (Table 2).

Sørensen analysis showed the protists communities from control soil and conventional management are very similar (close to 80\%) followed by conservation management (62\%). However, the community from organic management was identified as an outsider group (Fig. 2). 


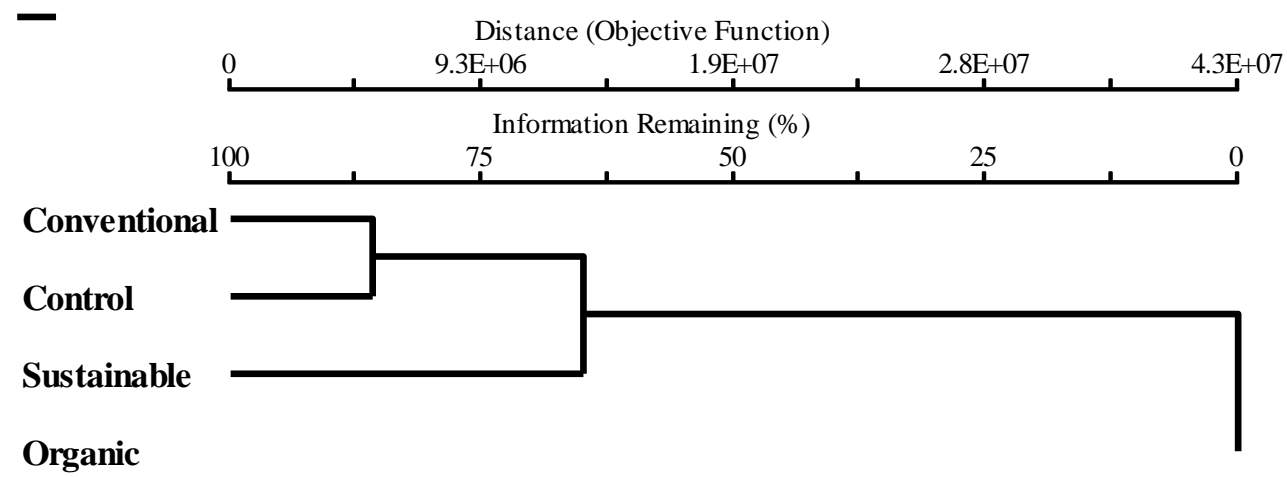

Fig. 2: Sørensen analysis linked the conventional agriculture management with control soil sharing $80 \%$ likeliness and this cluster was chained with the sustainable management with

62\% similarity. Protists community from organic management was linked with $0 \%$ similarity with the other 3 communities. This dendrogram was the most probable one after 999 repetitions of Sørensen analysis using the Monte-Carlo randomization algorithm in PC ORD® ver. 7 for Windows $®$.

Canonical Correspondence Analysis showed that the physical and chemical factors explained fewer than $10 \%$ of the MOTUs variances along the managements (data not shown) rather the soil moisture and rate of $\mathrm{C} / \mathrm{N}$ are the most important. On the other hand, the correlation of variances between abiotic factors was significant only for $\mathrm{pH}$ and moisture $(0.83)$.

Polar Ordination revealed species assemblage of protists communities't end to move from conventional management to organic one, and because of being at the left on the axis 1, move backwards to Sustainable management. Control soil is clearly depicted as an outside group because it is positioned in the extreme left, away from the MOTUs agglomeration zone (Fig. 3).

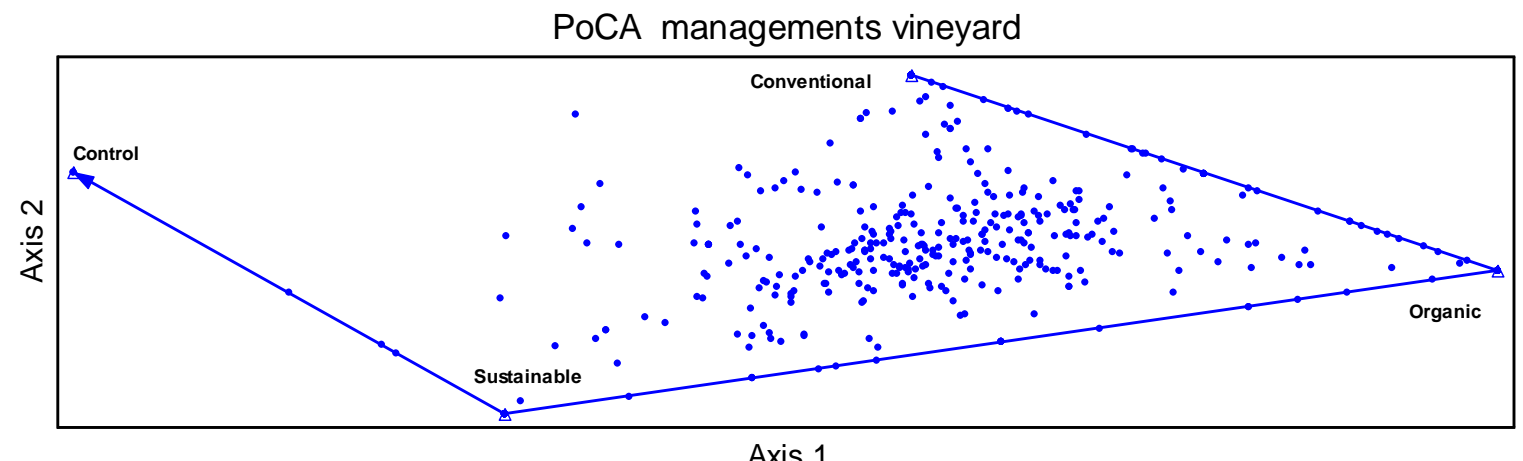

Fig. 3: Polar ordination analysis performed with $\mathrm{PC}$ ORD® ver. 7 for Windows ${ }^{\circledR}$ shows a line of development tendency of protists communities from the vineyards. This is also the most probable line after running 999 repetitions using the Monte-Carlo randomization 
International Journal of Agriculture and Environmental Research

ISSN: 2455-6939

Volume: 07, Issue: 04 "July-August 2021"

\section{algorithm in PC ORD® ver. 7 for Windows $®$. The tendency goes from the richest protists soil of conventional management to the even richer community of the organic one and then to the community of the sustainable agriculture. All of them far from the poorest community of the control soil.}

\section{DISCUSSION}

Soil management showed improvements in the chemical values needed for plant productivity such as soil moisture and organic matter content. These improvements are consequences of organic matter incorporation in all types of agriculture soils (FAO 2017) as well as the chemicals (pesticides, herbicides, or both) that might be added in conventional agriculture (Hamadttu, 2019). Salinity was scarcely affected by the type of agriculture as this factor is determined by the salt content in the soil layers beneath the cultivated one and its variation is controlled by cycles of water infiltration and evaporation. Improvements due to soil management were evident in the proportional content of organic matter and the $\mathrm{C} / \mathrm{N}$ rate, no matter the type of agriculture. However, the degree of the improvements is related to the type of soil management; for example, organic agriculture appeared to be best for improving the $\mathrm{C} / \mathrm{N}$ ratio in the soil matrix than sustainable agriculture. The differences in the amount of incorporation of organic matter between organic management and sustainable one may be due to the variation and frequencies of fertilizations in both forms of agriculture. No-tillage in sustainable agriculture slows down the incorporation of organic matter into the soil matrix, while compost and limited tillage in organic management allows for better incorporation of the fertilizer in the soil matrix. Notwithstanding, total organic matter content in all agriculture managements is impoverished with respect to the control soil because in the latter, organic matter has accumulated uninterrupted. The high $\mathrm{C} / \mathrm{N}$ ratio in conventional agriculture shows the effect of nitrogen enrichment with chemical fertilizers to increase the vineyard biomass, despite the impoverishment of organic matter content in the soil matrix.

Soil enrichment with organic fertilizers means higher variety of resources for bacteria (normally feeding on low molecular weight organics) and fungi (normally feeding on high molecular weight organics) to develop. Soils enriched in this way may sustain higher species richness of these microorganisms (Mbuthia et al., 2015), and this increase of microbial richness promotes a cascade effect on the protist diversity (Bonkowski, 2004). Consequently, because of the use of chemicals, we expected the organic and the sustainable management and even the control soil to bear higher species richness than the conventional agriculture. However, species richness was lowest in the control soil.

The soil perturbation, caused by agriculture management, seems to have the opposite consequence than expected, may be because the physical perturbation of soil structure creates 
International Journal of Agriculture and Environmental Research

ISSN: 2455-6939

Volume: 07, Issue: 04 "July-August 2021"

new places for colonization and exposes higher surface of the organic matter to microbial metabolization. This source of microbial resources equilibrates the destructive effects of herbicides and pesticides on sensitive species of protists by enhancing the growth of the tolerant ones. This in turn, changes the abundances of dominant protists in response to soil management. For example, Oxytrichidae sp1 and Litostomatea sp1 were much more abundant in control soil than any other protist and showed a small diminution of their relative abundance under agriculture soils. Meanwhile, Eugregarinoridasp 1 was dramatically favored by all managements, making it the dominant in all agriculture soils. This MOTU increased from a relative abundance of $0.5 \%$ in control soil to $12 \%$ in organic agriculture. Such increments may be due to the combination of increase on its food sources and reduction / elimination of its competitors. Both of these two situations are promoted by the addition of pesticides or herbicides in conventional agriculture. Use of pesticides and herbicides may produce the two-dimensional effect of reducing the population of sensitive dominant and common MOTUs while increasing the appearance of tolerant rare ones in conventional management. This is reflected in the highest value of ShannonWiener index $\left(\mathrm{H}^{\prime}=4.34\right)$ found in vineyards managed in the conventional way. The equal value of Shannon-Wiener index $\left(\mathrm{H}^{\prime}=4.04\right)$ observed in organic and sustainable managements seems to support the dual role of agrochemicals. On one side, the use of biofertilizers enhances the species richness, but on the other side, by avoiding the use of agrochemicals, several protists species out compete the ones that will remain as rare ones and eventually turn undetectable in the soil samples. These assumptions are also supported by the Simpson's diversity indexes (Table 2) of all agriculture managements. All of them got almost the same value (0.96) that can be interpreted as the community structure of dominant and common protists showing a similar response to agriculture management, at least in the number and proportions of MOTUs. However, the identities may tell a different story.

Soil enrichment for agriculture is one of the main causes promoting the increase of protist numbers and MOTUs richness. However, the type of organics and their quality (C/N content inorganic fertilizers) used in each management are important factors affecting the growth of fungi and bacteria (Mbuthia et al., 2015), that ultimately are the food source selecting the species of protists, and leading their community structure development.

It was expected that protozoa communities would form a continuum from conventional agriculture to organic, sustainable and control soil (a chained dendrogram). Instead, Sørensen analysis showed the conventional and control soil as closely-related communities (80\% similarity) followed by sustainable management $(65 \%)$, while sending the community from organic agriculture as outsider group. These groupings support the notion that the protist's increase of numbers is the first response to soil management and species turnover follows depending on the perturbation intensity and frequency (Foissner, 1997). In the case of 
International Journal of Agriculture and Environmental Research

ISSN: 2455-6939

Volume: 07, Issue: 04 "July-August 2021"

agriculture, the quantity and quality of the chemicals and/or biotic fertilizers added to soils, their motility in the system, and their residual effects on microbial food sources will shape the protest community (Foissner, 1994; 1997). This can easily be the cause of the high species turnover ( $\beta=$ 123 to 132) calculated between the control soil and the agriculture managements. Visualizing this high level of species turnover together with the Sørensen analysis confirms that each type of agriculture management produces one community of protists that can be distinguished from each other.

Soil's water content is one of the main factors driving protist quantity and diversity as well as all biological activity in terrestrial ecosystems (D'Odorico et al., 2010), even more in arid regions (Whitford, 2002). Water is essential for microorganisms to get physiologically active (Makhalanyane et al., 2015), although water availability alone does not discriminate between species adapted to the same habitats, explaining its poor explicative correlation in the CCA. The $\mathrm{C} / \mathrm{N}$ ratio, on the other hand, may be used to distinguish nutritional needs between species. However, soil moisture and $\mathrm{C} / \mathrm{N}$ rate are so unspecific that they were identified by the CCA as being the two most important factors in the ordination but explaining less than $10 \%$ of the MOTUs variance (data not shown). The $\mathrm{C} / \mathrm{N}$ rate is indirectly linked to the soils organic matter content because it depends on the $\mathrm{N}$ content and the size of the organic molecules containing it. Consequently, it may be needed to determine the main groups of organic molecules added as fertilizers to find better correlations between chemical factors and dominance of protists species in soils.

Polar ordination draws one development tendency of soil protists communities under agriculture management. The conventional management having the highest diversity may get a sort of MOTUs impoverishment when avoiding agrochemicals and adding biofertilizers. This in turn, makes the protist community to approach a structure more like the control soil, although more diverse nonetheless; especially when tillage is also ruled out allowing soil to keep their structure free of periodical perturbations.

We concluded that, although the organic matter content increased from conventional, to organic to sustainable management, the $\mathrm{C} / \mathrm{N}$ rate was more important for structuring two different protists community in both conservation managements that were also different from the conventional agriculture.

\section{REFERENCES}

Foissner, W. 1994. Soil protozoa as bioindicators in ecosystems under human influence. In: Darbyshire J.F. (Ed.), Soil Protozoa, CAB International, Wallingford, Oxon, England, pp.147-193 
International Journal of Agriculture and Environmental Research

ISSN: 2455-6939

Volume: 07, Issue: 04 "July-August 2021"

Foissner, W. 1997. Protozoa as bioindicators in agroecosystems, with emphasls on farming practices, biocides, and biodiversity. Agriculture, Ecosystems and Environment 62; 93103

Coleman, D.C. (1994). The microbial loop concept as used in terrestrial soil ecology studies. Microbial Ecology 28, 245-250.

Crotty, F.V., Adl, S.M., Blackshaw, R.P., Murray, P.J., (2012). Protozoan pulses unveil their pivotal position within the soil food web. Microbial Ecology 63, 905-918.

Sina M. Adl*, Andrea Habura, Yana Eglit. 2014. Amplification primers of SSU rDNA for soil protists. Soil Biology and Biochemistry. 69; 328-342.

Boye, J.I. \&Arcand, Y. (2013). Current Trends in Green Technologies in Food Production and Processing. Food Eng Rev 5: 1-17 https://doi.org/10.1007/s12393-012-9062-Z

FAO Strategic Programme to make Agriculture, Forestry and Fisheries more Productive and Sustainable (2017). Strategic work of FAO for sustainable food and agriculture. Pathways to Sustainable Food and Agriculture. P.p 6 - 15

Hamadttu Abdel Farag El-Shafie (March 15 ${ }^{\text {th }}$ 2019). Insect Pest Management in Organic Farming System [Online First], IntechOpen, DOI: 10.5772/intechopen.84483. Available from: https://www.intechopen.com/online-first/insect-pest-management-in-organicfarming-system

Jacoby R, Peukert M, Succurro A, Koprivova A, Kopriva S. The Role of Soil Microorganisms in Plant Mineral Nutrition-Current Knowledge and Future Directions. Front Plant Sci. 2017:8:1617. Published 2017 Sep 19. Doi:10.3389/fpls.2017.01617

Michael Bonkowski (2004). Protozoa and plant growth: The microbial loop in soil revisited. New Phytologist 162(3):617-631. DOI: 10.1111/j.1469-8137.2004.01066.x

Lilian WanjiruMbuthia, Veronica Acosta-Martínez, Jennifer De Bruyn, Sean Schaeffer, Donald Tyler, EvahOdoi, MolefiMpheshea, Forbes Walker, Neal Eash (2015).Long term tillage, cover crop, and fertilization effects on microbial community structure, activity: Implications for soil quality. Soil Biology and Biochemistry 89: 24-34. https://doi.org/10.1016/j.soilbio.2015.06.016

Peck, J. E. (2010). Multivariate analysis for Community Ecologists: step by step using PC ORD. MJM Software Design, Gleneden Beach, OR. 162 pp. 
Simone Fattorini (2005). A simple method to fit geometric series and broken stick models in community ecology and island biogeography. Acta Oecologica 28(3):199-205. DOI: $10.1016 /$ j.actao.2005.04.003

Paolo D'Odorico, Francesco Laio, AmilcarePorporato, Luca Ridolfi, Andrea Rinaldo, Ignacio Rodriguez-Iturbe (2010). Ecohydrology of Terrestrial Ecosystems. BioScience, 60: 898907, https://doi.org/10.1525/bio.2010.60.11.6

Thulani P. Makhalanyane, Angel Valverde, EoinGunnigle, Aline Frossard, Jean-Baptiste Ramond, Don A. Cowan (2015). Microbial ecology of hot desert edaphic systems. FEMS Microbiology Reviews 39: 203-221. https://doi.org/10.1093/femsre/fuu011

Withford, Walter (2002). Ecology of desert systems, Academic Press, 343 P. Hardcover ISBN: 9780127472614

Burki et al., (2020). The new tree of eukaryotes. Trends in Ecology \& Evolution 35: 43 - 55 